\title{
Dialogicidade formal como possibilidade para a liberdade da palavra em práticas de justiça
}

\author{
Ana Beatriz Ferreira Dias* \\ Valdemir Miotello*
}

\begin{abstract}
Resumo
Neste trabalho, analisamos elementos estruturais da comunicação ideal entre vítimas, ofensores e suas comunidades de apoio propostos pela justiça restaurativa, uma abordagem bastante recente no Brasil que vem crescendo significativamente na última década. Ao eleger o diálogo entre os sujeitos como fundamental para a resolução e prevenção de situações de violência, o movimento restaurativo surge como uma resposta contrária ao atual modelo retributivo de justiça, altamente punitivo, abstrato e monológico, vigente há séculos. Instigados com as orientações do movimento restaurativo acerca da comunicação face a face entre os sujeitos mais diretamente envolvidos no dano, problematizamos a possibilidade da liberdade da palavra em práticas restaurativas. Para tanto, buscamos compreender as orientações para a realização de uma prática de justiça restaurativa intitulada "Círculo Restaurativo". Analisamos materiais didáticos voltados à formação de coordenadores de Círculos Restaurativos propostos pelo Programa Justiça para o Século 21, por meio de sua Central de Práticas Restaurativas do Juizado Regional da Infância e da Juventude de Porto Alegre (RS). Este trabalho de compreensão se dá fundamentado teórica e metodologicamente nos estudos bakhtinianos. Mobilizando, sobretudo, o conceito de dialogicidade formal, consideramos que o Círculo Restaurativo oferece condições técnicas que podem levar à emergência de várias vozes no processo de justiça, contribuindo com uma maior liberdade da palavra em instâncias judiciárias.
\end{abstract}

Palavras-chave: Interação verbal. Dialogicidade formal. Liberdade da palavra.

Entre o risco e aprisco, há que se apostar no risco. Pela primeira vez na história há, tecnicamente, a possibilidade de dizer e deixar à disposição dos outros um discurso, cujas profundezas são intraduzíveis, mas que se abrem como espaço de diálogo de palavras e contrapalavras. (GERALDI, 2010b, p. 199).

* Universidade Federal da Fronteira Sul/Campus Cerro Largo (UFFS).

** Universidade Federal de São Carlos (UFSCar). 


\section{Considerações iniciais}

$\mathrm{Na}$ última década, despontam inúmeras práticas de justiça restaurativa em várias partes do mundo, propondo novas alternativas de interações verbais como tática para enfrentar situações de violência em escolas, sistemas judiciários, comunidades, entre outras tantas organizações governamentais e não governamentais. Como resposta contrária às relações sociais altamente punitivas, de natureza abstrata e autoritária construídas pela abordagem dominante de justiça atual e vigente há séculos (denominada por estudiosos da área como "justiça retributiva"), as experiências com justiça restaurativa fazem parte de um amplo "movimento descentralizado e informal de justiça" (NETO, 2004, p. 36) que vem mobilizando uma diversidade de profissionais, lideranças e organizações na implementação de modos não violentos de resolução de conflitos que sejam baseados na negociação de sentidos sobre os fatos, no diálogo, na construção de um espaço em que as verdades possam ser enunciadas pelos sujeitos diretamente envolvidos no dano. ${ }^{1}$

Como observa Schuch (2001), a implementação da justiça restaurativa no Brasil vem mobilizando, desde o início desse movimento, sujeitos com diversas formações e atuações profissionais, de modo que podemos observar a "formação de um novo campo de intervenção em desenvolvimento" que reúne "agentes judiciais, organizações de desenvolvimento e de proteção aos direitos humanos com abrangência transnacional, professores, líderes comunitários, especialistas e consultores internacionais, clube de mães", etc. Tendo isso em vista, acreditamos que o campo da justiça restaurativa possa ser incluído como um dos lugares para o exercício da pesquisa em linguagem na contemporaneidade. Principalmente porque as práticas restaurativas acontecem na e pela linguagem, linguistas podem se ocupar das mais variadas dimensões da comunicação em novas práticas de justiça.

Com isso, podemos contribuir com a exploração e compreensão de interações verbais marcadas por situações de violência e, também, alargarmos as possibilidades da pesquisa em linguagem na contemporaneidade. Como observa Geraldi (2010a, p. 52), a linguística, sobretudo porque parece estar abandonando

1 Para compreensão do histórico do movimento restaurativo no Brasil, sugerimos leituras de textos elaborados por pesquisadores e profissionais que, ligados à área do Direito, vêm liderando esse movimento, como Leoberto Brancher, Beatriz Gershenson Aguinsky, Renato Campos Pinto De Vitto, Pedro Scuro Neto, entre outros. 
"o sonho da cientificidade, da objetividade e das fórmulas prontas", rejeitando, com isso, a noção estruturalista de língua enquanto sistema de signos linguísticos, vem passando por um "rearranjo profundo [...] em seus programas de pesquisa e modos de definir seus objetos, suas metodologias e seus parentescos disciplinares". Nesse contexto de produção do conhecimento linguístico, "certamente estamos reconstruindo parentescos, reencontrando novas parcerias", fazendo, enfim, "outros pactos com os estudos da ordem das humanidades". Entendemos, assim como esse pesquisador, que a linguística, ao abrir-se para o diálogo com outras áreas, pode ver o seu campo de estudos alargado, com novas possibilidades de compreender o homem e suas realidades, mantendo a linguagem como seu objeto de estudo.

Diante disso, a presente pesquisa propõe a compreensão de elementos da comunicação propostos por iniciativas em justiça restaurativa, tomando como base fundamentos teórico-metodológicos dos estudos linguísticos. Mais especificamente: com base nos estudos bakhtinianos, ${ }^{2}$ buscamos compreender a estrutura comunicacional de práticas de justiça restaurativa instauradas no sistema penal. Essa escolha foi feita considerando que são as instituições judiciárias que mais irradiam o movimento restaurativo brasileiro. Ainda que o objetivo deste trabalho não seja explorar o amplo panorama de emergência dessa nova prática, é importante mencionar que foi em instituições judiciárias que o movimento restaurativo brasileiro surgiu e onde, ainda hoje, os esforços são sistematicamente concentrados.

A seguir, vamos apresentar, mais especificamente, a problemática central desta pesquisa, a questão da liberdade da palavra em práticas restaurativas inseridas em instâncias de justiça retributiva. Além disso, pontuamos a iniciativa em justiça restaurativa de que nos ocupamos para construir compreensões em torno dessa questão.

2 Compreendemos a significação do adjetivo "bakhtiniano" no sentido proposto por Ponzio (2011, p. 46). Na visão desse pensador, o termo deve ser entendido, antes de tudo, no contexto de produção intelectual realizada por um grupo de sujeitos que, em "uma intensa e afinada colaboração", trabalhava em "pesquisas comuns, a partir de interesses e competências diferentes". Esse grupo de artistas, intelectuais e cientistas reunia-se, em vários e diferentes contextos sociais e políticos na Rússia, e teve intensa produção principalmente entre as décadas de 1920 e 1930. Ainda que tenha sido fundado por esse grupo de amigos, os estudos bakhtinianos mantêm-se vivos nos dias de hoje, em um novo contexto de produção intelectual. Nas vozes de uma série de pesquisadores que vêm apresentando sua leitura da obra de Bakhtin e de seus parceiros, ressoam e são ressignificadas vozes desse grupo de intelectuais que, há mais de um século, encontravam-se para construir formas de pensar o mundo. 


\section{Procurando a liberdade da palavra em práticas de justiça}

Instigados com as novas dinâmicas de comunicação entre vítimas, ofensores e suas comunidades de apoio propostas pelo movimento de justiça restaurativa, as questões em torno das quais, neste trabalho, construímos possíveis respostas podem ser formuladas nos seguintes termos: é possível que práticas de justiça restaurativa criem um espaço de livre circulação da palavra? em uma sociedade como a nossa, em que dizeres são interditados em nome da manutenção da "ordem do discurso", os sujeitos podem enunciar suas verdades únicas em práticas de justiça? É possível, enfim, a "liberdade da palavra" em práticas de justiça restaurativa inseridas no sistema estatal de justiça, marcado hegemonicamente pelo fazer retributivo de justiça?

Aqui a distinção entre os sintagmas "liberdade da palavra" e "liberdade de palavra" proposta por Ponzio (2010) contribui para demarcar o objetivo deste trabalho. Na visão do estudioso, a liberdade de palavra diz respeito ao cerceamento, ao controle e à propriedade da palavra, em que esta faz parte dos

lugares-comuns da ordem dos discursos e pressupõe um sujeito proprietário, patrão, fiscal, das palavras, que "toma a palavra", a "passa", a "concede", que tranquiliza dizendo "te dou a minha palavra", e permite o diálogo dizendo "é suficiente falar disso" e que sempre com a mesma expressão "não se fala mais nisso", o quebra (PONZIO, 2010, p. 13).

Isso leva, em última análise, ao "desconhecimento do outro, recusa do tempo disponível para o outro, negação do tempo do outro, recusa ou incapacidade de escuta, de escuta da própria alteridade e da alteridade alheia", afirma Ponzio (2010, p. 78). Esse é o modo de vida dominante no mundo contemporâneo e que encontra máxima expressividade na maioria dos processos judiciais ancorados no modelo retributivo, tradicional, de justiça.

A liberdade da palavra é posição diferente. Ela busca restituir, de fato, a liberdade da palavra, do seu direito à alteridade, de sua autonomia, do seu estranhamento. É palavra que enuncia suas verdades, únicas e singulares, assume o direito de ser não funcional, livre das amarras de identidades que aprisionam os sujeitos em dados grupos e classes. É contrapalavra às pretensões egoístas e arrogantes do sujeito que, defendendo o seu direito à "liberdade de palavra", age como proprietário e dono da palavra para atuar sobre ela e, consequentemente, para atuar sobre os sujeitos outros. 
Desse modo, o problema que levantamos ao longo deste trabalho remete a uma provocação já levantada por outros pesquisadores em linguagem, como Geraldi e Ponzio, acerca da libertação da palavra em uma sociedade que, com seus discursos e práticas hegemônicas de exercício do poder, aprisiona sujeitos e suas relações a uma existência dominada pela lógica do silêncio opressor. Essa é a lógica que predomina no sistema judiciário, que normalmente nega aos sujeitos mais diretamente envolvidos no dano, vítimas e ofensores, seu direto à expressão, afinal um profissional é designado como o seu porta-voz.

Mesmo que as experiências de justiça restaurativas sejam bastante heterogêneas entre si, variando conforme vários fatores, como aqueles ligados à relação social em sua eventicidade e ao contexto de implantação e de realização, é possível observar certa homogeneidade no movimento restaurativo devido ao conjunto de pressupostos teóricos e metodológicos que estruturam as práticas restaurativas, como assinalam estudiosos da área, como Zehr (2008), Neto (2004) e Schuch (2008). Assim, entendemos que é possível contribuir com a compreensão de interações verbais emergentes no contexto judiciário, tomando como base a abordagem teórica e metodológica da justiça restaurativa, que sustenta as suas práticas.

Tendo isso em vista, buscamos compreender pressupostos teóricos e metodológicos da justiça restaurativa referentes às ações comunicativas que compõem a modalidade de prática restaurativa intitulada "Círculo Restaurativo". Analisamos orientações para realização de dinâmicas de comunicação no Círculo Restaurativo propostas pela Central de Práticas Restaurativas do Juizado Regional da Infância e da Juventude de Porto Alegre (CPR/JIJ), vinculada ao Programa Justiça para o Século 21 (J21). Fundamentado em princípios de justiça restaurativa, o J21 divulga e realiza práticas de justiça restaurativa, em Porto Alegre (RS), como tática de enfrentamento e prevenção de situações de violência. Com reconhecida contribuição para a difusão e consolidação do movimento restaurativo não apenas no território regional, mas também nacional e até internacional, esse programa destaca-se na implantação de práticas de justiça restaurativa no sistema jurídico, mais especificamente, no atendimento ao adolescente em conflito com a lei.

Para compreender esse ideário do movimento de justiça restaurativa, tomamos como base textos que, publicados pelo J21, servem como subsídios para atividades de capacitação de coordenadores de procedimentos restaurativos. Linguagem verbal e não verbal que constituem esses materiais de formação foram centrais 
para a análise e, como tal, são os objetos de estudo privilegiados nesta pesquisa. Pontuar o objeto empírico é o primeiro passo do percurso interpretativo, afinal "não há análise de discurso sem discurso, afirma Geraldi (2012, p. 32). E mais: "antes de mais nada, um estudo bakhtiniano [como este que buscamos desenvolver] não existe sem um objeto empírico que é preciso ter presente", afirma o pesquisador.

Assim, não podemos deixar de destacar que as materialidades, entendidas aqui como objetos empíricos, são constituídas, neste trabalho, por um universo particular, o "universo dos signos", conforme expressão empregada por Bakhtin/ Volochínov (2009). Para o Círculo de Bakhtin, o signo não só é um produto ideológico que "faz parte de uma realidade (natural ou social) como todo corpo físico, instrumento de produção ou produto de consumo", mas também é uma materialidade semiótica, ideológica, carregada, portanto, de dada maneira, de dado ponto de vista axiológico acerca dos acontecimentos.

Além disso, é fundamental para o desenvolvimento deste estudo, compreender que todo e qualquer signo ideológico, como a palavra e a imagem, é composto tanto por uma parte verbal quanto por um horizonte extraverbal. Porque a palavra é também constituída de situações extraverbais, o pesquisador precisa compreender elementos do meio social mais amplo e imediato que parecem constituir a enunciação. Ao contar com situações extraverbais para compreender o texto, o pesquisador traz, consequentemente, vários outros textos que compõem esses horizontes sociais para contrapor ao enunciado em sua dimensão verbal.

A compreensão dos enunciados será maior na medida em que o pesquisador conseguir "ampliar os contextos", ou seja, fazer emergir "mais vozes do que aquelas que são evidentes na superfície discursiva", não para encontrar a "fonte do dizer", mas para fazer dialogarem textos, "diferentes vozes", afirma Geraldi (2012, p. 29-33). Esse estudioso da linguagem entende esse passo como o ato do pesquisador em "cotejar textos com outros textos". Dar contextos a um texto é, segundo o pensador, "cotejá-lo com outros textos". Quanto mais "cotejamentos", maior a profundidade de compreensão. Com isso, é possível retomar alguns nós interpretativos que compõem a cadeia infinita da comunicação entre enunciados, encontrando "enunciados a que o texto responde, a que se contrapõe, com que concorda, com quem polemiza, que vozes estão aí sem que se explicitem porque houve esquecimento da origem" (GERALDI, 2012, p. 33).

Para compreender elementos da comunicação da nova abordagem de justiça, além de propormos o cotejo entre textos (como linguagem verbal e não verbal dos materiais de formação do J21) voltados à formação de coordenadores 
quanto à estrutura da interação verbal em Círculos Restaurativos, perspectivas teóricas dos estudos bakhtinianos e da área de justiça restaurativa são vozes que constituem a interpretação que realizamos e, como tal, integraram o cotejamento entre enunciados. Mobilizamos, sobretudo, o conceito de dialogicidade, mais especificamente, de dialogicidade formal proposta por Ponzio et al. (2007) a partir dos estudos do Círculo de Bakhtin para buscar aprofundar a compreensão das interações verbais em Círculos Restaurativos.

A partir da realização desse estudo, sugerimos, ao longo deste trabalho, que práticas de justiça restaurativa podem ser entendidas como encontros de palavras potencialmente marcados pela dialogicidade formal. Com isso, o movimento restaurativo cria condições para contribuir com a redução da liberdade de palavra, característica do modelo atual de justiça retributiva, e promover uma maior liberdade da palavra.

Para melhor apresentar o cotejamento entre textos, que levou a tal interpretação, desenvolvemos as compreensões de modo a colocar em diálogo, de um lado, os elementos sócio-históricos que determinaram, em grande medida, as enunciações referentes a novas táticas de comunicação para resolução de conflitos e, de outro, os elementos verbais e não verbais dessas enunciações, como construções linguísticas e imagens integrantes de materiais de formação de coordenadores.

\section{Central de Práticas Restaurativas}

As orientações referentes à realização da comunicação em Círculo Restaurativo que neste trabalho analisamos fazem parte das atividades de capacitação da CPR/ JIJ, vinculada ao Juizado da Infância e da Juventude da Comarca de Porto Alegre, que vem adotando práticas restaurativas em atendimentos de jovens em conflito com a lei. No âmbito da CPR/JIJ, a "capacitação" é o segmento que cria espaços para estudos, discussões e aprofundamentos em torno da justiça restaurativa, com os objetivos de: divulgar o J21; sensibilizar comunidades sobre princípios e práticas dessa nova abordagem de justiça; formar lideranças em justiça restaurativa; apoiar iniciativas voltadas à criação de grupos de estudos; formar novos coordenadores de práticas restaurativas por meio de subsídios teóricos e práticos. A equipe dessa central de práticas restaurativas desenvolve atividades que vão desde a divulgação do projeto e a sensibilização de comunidades sobre os ideais da nova abordagem de justiça até os processos de ensino/aprendizagem de temas da justiça restaurativa (OLIVEIRA, 2009). 
A ideia é a CPR/JIJ manter-se subsidiariamente como espaço de capacitação e difusão operacional de práticas e princípios em justiça restaurativa oferecido tanto para operadores do sistema judicial quanto para aqueles ligados aos serviços não judiciais de atendimento a adolescentes em conflito com a lei. Assim, dentre as ações desenvolvidas por esse eixo, constam: cursos de iniciação em justiça restaurativa, programa de formação de coordenadores de Círculos Restaurativos e realização de eventos, como congressos. Em muitas dessas atividades, são apresentadas, portanto, orientações para que os coordenadores de práticas restaurativas realizem o Círculo Restaurativo.

É importante destacar que a CPR/JIJ, assim como outras centrais de práticas restaurativas, foi criada em caráter experimental com os objetivos principais de contribuir com a expansão e consolidação do movimento de justiça restaurativa, fomentar a sustentabilidade e a emancipação das instituições parceiras do J21 que adotaram práticas restaurativas em suas rotinas de trabalho. Assim, o J21 contou com as CPRs como importantes táticas para descentralização de certas atividades que apenas ele, de forma geral, executava até então.

Assumindo tais perspectivas, o J21 dedica-se, com frequência, desde o princípio de suas atividades, à mobilização e à formação de recursos humanos com a finalidade de construir meios para prevenir e resolver situações de violência em que estejam envolvidas crianças e/ou adolescentes. Para irradiar a visão restaurativa de justiça e participar da construção da autonomia das instituições parceiras do programa, o J21 contou com um número bastante significativo de participantes nas atividades de formação. Podemos ter uma ideia da abrangência do movimento restaurativo impulsionado por esse programa por meio de alguns dados. Consta no relatório das atividades de 2013 realizadas pelo J21 (CPR/JIJ, 2013, p. 3) que aproximadamente 9.184 pessoas foram capacitadas pelo programa, entre os anos de 2005 e 2012, em modalidades de cursos presenciais. Desses participantes, vieram sujeitos de vários estados do país.

\section{Procedimento Restaurativo}

O Círculo Restaurativo desenvolvido pela CPR/JIJ é uma das etapas do Procedimento Restaurativo, o qual é entendido pelo J21 (2008b, p. 8) como um amplo "espaço de diálogo e comunicação" cujo uso da linguagem "tem um grande significado em todas as dinâmicas". O Procedimento como um todo é composto por três grandes fases: o Pré-círculo Restaurativo, o Círculo Restaurativo e o Pós- 
círculo Restaurativo. A participação dos sujeitos se dá de forma voluntária em todas essas fases do processo, de modo que cada um decide se participará ou não dos encontros.

O Pré-círculo é o primeiro contato entre coordenador e participantes do procedimento. Essa etapa acontece por meio de encontros, em distintos momentos, do coordenador com o ofensor, a vítima e as suas respectivas comunidades de apoio para buscar construir convergências de narrativas sobre: o fato ocorrido (como reconhecimento da autoria do ato infracional e dos sujeitos presentes no momento da violência), a vontade de cada sujeito em participar voluntariamente do encontro, as pessoas cujas presenças seriam ou não importantes no encontro, consenso sobre os sujeitos que podem ou não ser convidados a participar. Essa etapa dá condições para que ocorra o Círculo, segunda etapa do procedimento.

O Círculo Restaurativo é o encontro propriamente dito entre os sujeitos mais diretamente envolvidos no dano e suas comunidades de apoio, conduzido por um coordenador e, algumas vezes, por um cocoordenador, com os objetivos de: criar um espaço de diálogo; buscar a compreensão dos acontecimentos passados e suas consequências na vida de cada um dos participantes; construir, em comum acordo, um plano de ações que contribua na redução dos impactos resultantes do dano; humanizar os sujeitos e suas relações. De todas as etapas do procedimento, o Círculo é normalmente considerado a principal delas.

Por fim, há o Pós-círculo, última etapa do Procedimento Restaurativo. Esse encontro é realizado para que os participantes do Círculo avaliem o andamento do acordo, elaborado na etapa anterior, no Círculo. No diálogo do Pós-círculo, os sujeitos discutem principalmente se o acordo foi ou não cumprido, se estão ou não satisfeitos com os resultados do procedimento. Se o acordo realizado no Círculo for considerado cumprido, o procedimento restaurativo encerra-se nessa etapa do Pós-círculo. Caso contrário, os participantes podem elaborar novos acordos e, com isso, propor novas ações. Além de voltar-se à facilitação da comunicação entre os participantes, o coordenador deve registrar o andamento do encontro em documento próprio a esse fim, inserindo as possíveis sugestões e adaptações aos acordos.

A seguir, descrevemos o funcionamento do Círculo Restaurativo quanto à estrutura das interações verbais preconizadas em materiais de formação de coordenadores para que possamos identificar e compreender a dialogicidade formal dessa prática de justiça. 


\section{Dialogicidade formal no Círculo Restaurativo}

É preciso ter em vista, antes de tudo, que todo e qualquer texto é, em alguma medida, dialógico, afinal ele é produzido em relação com outros tantos textos e também é constituído na relação com outros enunciados. Conforme essa perspectiva bakhtiniana, Ponzio explica, então, que todo texto é mais ou menos dialógico por duas razões:

1) porque produzido em relação, quer pela forma (gênero do discurso, gênero literário, estilo, organização sintática), quer pelo conteúdo, com outros textos, que ele resgata, imitando-os, manipulando-os, aceitando-os, reportando-os, conformando-se a eles, ou então distanciando-se deles. E, além disso, 2) porque um texto verbal é organizado não só segundo relações lógico-sintáticas entre enunciações, mas também relações dialógicas entre elas, quer se trate das enunciações explicitamente presentes no texto, quer das subentendidas, coisa que ele previne enquanto possíveis objeções, possíveis pedidos de esclarecimento, de explicação, etc. (PONZIO et al., 2007, p. 203).

Com base no caráter dialógico do enunciado/texto, o estudioso destaca que podemos falar em duas acepções de dialogicidade, as quais podem estar em relação na produção do sentido de dada materialidade sígnica. Para o autor, um texto pode ser considerado dialógico tendo em vista, de um lado, a sua forma, a sua representação formal. Incluindo o diálogo formal entre réplicas, esse tipo de dialogicidade "reproduz a troca de tiradas entre dois ou mais interlocutores, quer na forma do discurso direto, quer na forma do discurso indireto e das suas variantes". Nesse caso, trata-se do diálogo na sua acepção mais comum, como sucessão entre diferentes enunciados, no qual um sujeito fala e, em seguida, o outro. Uma vez que o diálogo como forma pode ser encontrado em vários gêneros do discurso, como "na conversa cotidiana, no gênero do debate, nos textos narrativos, nos gêneros dramáticos, no gênero do diálogo" (PONZIO et al., 2007, p. 204), podemos incluir o Círculo Restaurativo, devido às suas características, como uma das práticas constituídas, em grande medida, pela dialogicidade formal entre enunciados.

A segunda concepção de diálogo não está relacionada a uma dimensão formal, mas sim à condição de inevitável encontro com a palavra do outro, que, de alguma maneira, altera a identidade do eu. A dialogicidade substancial existe enquanto grau, e não enquanto forma. Todo texto, oral e escrito, possui seu grau de dialogicidade substancial, de modo que existem textos com efeitos de sentido 
monológicos ou dialógicos: o monologismo diz respeito a estratégias discursivas voltadas a construírem um texto no qual predomina uma só voz, uma só tese, um só percurso interpretativo como válido. Já os textos com tendências dialógicas são tecidos a partir de táticas discursivas que colocam em cena uma diversidade de valorações e percursos interpretativos.

Para os propósitos do presente trabalho, vamos abordar o Círculo Restaurativo como um espaço cuja dialogicidade formal cria condições para que os sujeitos mais diretamente envolvidos no dano, ofensor e vítima, tenham o direito de fala, ou seja, o direito de construir o seu percurso interpretativo sobre os fatos, os outros enunciados, as outras verdades. Essa escolha, voltada à discussão da dialogicidade formal, não quer dizer ausência da dialogicidade substancial naquela prática de justiça. Em trabalho anterior (2014), produzido ao longo do curso de doutoramento em linguística, analisamos casos concretos de justiça restaurativa e observamos a relação entre dialogicidade formal e substancial na produção de sentidos. Isso levou à criação de um espaço marcado pela busca do direito à alteridade, essencialmente voltado à liberdade da palavra. ${ }^{3}$

No presente trabalho, portanto, nossas compreensões são centradas na dialogicidade formal do Círculo, entendida como possibilidade técnica que tende a contribuir para a liberdade da palavra. Considerando que a maneira de resolução de conflito dominante em nossa sociedade normalmente impede os sujeitos mais diretamente envolvidos em crimes e ato infracionais de dialogarem diretamente entre si sobre os fatos, podemos afirmar que a dialogicidade formal em práticas restaurativas parece abrir possibilidades de circulação da palavra, em que os sujeitos podem enunciar verdades, por si próprios, colaborando no encaminhamento e solução de dado problema.

Para realizarmos essas interpretações, levamos em conta principalmente as orientações ideológicas propostas pelo J21 no seu roteiro de sistematização sobre o funcionamento do Círculo Restaurativo. O roteiro para realização do Círculo Restaurativo é uma materialidade capaz de sugerir a tendência dessa prática para o diálogo formal. Para subsidiar o desenvolvimento de práticas restaurativas, a CPR/ JIJ elaborou uma sistematização dos momentos que, do seu ponto de vista, são

3 Para fins de contextualização deste estudo, é importante destacar que o presente trabalho é uma reformulação de parte da pesquisa de doutoramento realizada por Dias (2014), com a orientação do professor orientador Valdemir Miotello, entre 2010 e 2014. A tese intitulou-se "Encontro de palavras em procedimentos restaurativos - uma visão possível sobre a linguagem e seu funcionamento" e teve como objetivo geral analisar a linguagem e seu funcionamento em dois Círculos Restaurativos, com a participação efetiva de vítimas, ofensores e suas comunidades de apoio. 
fundamentais para a condução da comunicação no Círculo Restaurativo. Como uma espécie de roteiro, essa sistematização serve de subsídio aos coordenadores para que esses conduzam a interação verbal entre os participantes. Ainda que essas orientações possam ser encontradas em várias publicações do J21, estão apresentadas, com mais detalhamento do funcionamento da prática, nas referências Iniciação em justiça restaurativa (2008a) e Manual de práticas restaurativas (2008b), que tomamos como base para realizar as leituras.

O roteiro, para o programa de justiça restaurativa (2008b, p. 38), serve "para reforçar a autoconfiança do coordenador e para preservar os princípios e valores restaurativos essenciais ao sucesso do procedimento". Isso não quer dizer que o cumprimento do roteiro, com a "aplicação" dos principais momentos do Círculo, garanta, por si só, resultados com alto grau de restauratividade. O J21 elaborou a sistematização do Círculo com a finalidade de oferecer materiais de apoio com características didáticas e operacionais que auxiliem os coordenadores a facilitar a interação entre os sujeitos. Nesse sentido, entendemos que o roteiro parece ser concebido, pelo J21, no quadro da eventicidade das relações sociais, afinal esse programa de justiça assume que a "justiça restaurativa é eminentemente vivencial” e diz respeito a práticas sociais vivenciadas na concretude e unicidade das interações.

A seguir, destacamos, então, a sistematização do Círculo elaborada pelo J21 para que observemos elementos que constroem a dialogicidade formal dessa prática de justiça. Com base nas características relativamente estáveis do Círculo Restaurativo, o J21 propõe que esse encontro de justiça seja composto por três grandes momentos, designados com a seguinte terminologia: "compreensão mútua", "autorresponsabilização" e "acordo". No primeiro momento, busca-se que os sujeitos discutam acontecimentos passados que geraram consequências na vida de cada um deles e se compreendam mutuamente sobre tal tema. Cada sujeito é convidado a falar das consequências que o dano produziu em sua vida, buscando identificar possíveis necessidades, ainda não atendidas, que poderiam reduzir o impacto da situação que lhe é adversa.

De uma forma geral, três são as grandes provocações em torno das quais o diálogo irá se desenvolver, nesse primeiro momento do Círculo, conforme roteiro do J21: 
FIGURA 1 - Primeiro momento do Círculo Restaurativo.

COMPREENSÃO MÚTUA - Foco nas necessidades atuais
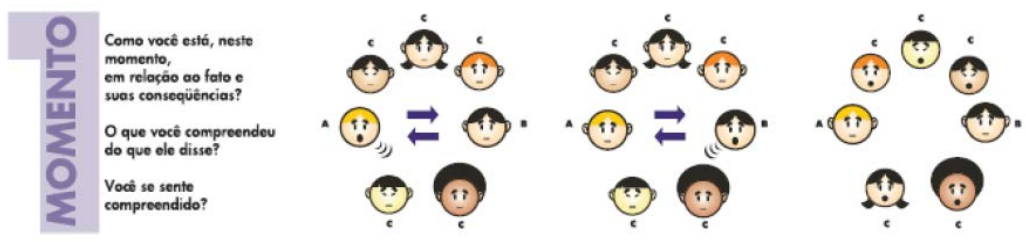

FONTE: Folder Justiça para o século 21: Instituindo práticas restaurativas, 2007. In: JUSTIÇA PARA O SÉCULO 21, 2008c.

Na figura acima, notamos que o movimento do Círculo se dá a partir de perguntas feitas pelo coordenador, as quais são resumidas da seguinte forma: "Como você [interlocutor A], está, neste momento, em relação ao fato e suas consequências?"; "O que você [interlocutor B] compreendeu do que ele [interlocutor A] disse?"; "Você [interlocutor A] se sente compreendido?". Representando já a dialogicidade formal da comunicação, essas perguntas são destinadas, sequencial e ordenadamente, aos interlocutores do processo comunicativo: vítima, ofensor e pessoas da comunidade de apoio.

Normalmente, o coordenador inicia a dinâmica da conversa convidando o sujeito que, para ele, parece enfrentar maior sofrimento, naquele momento da enunciação, resultante das consequências dos fatos. Inicia-se, na maior parte das vezes, ou pela vítima ou pelo ofensor. Para explorarmos essa dinâmica, suponhamos que à vítima sejam destinadas as provocações para repensar o passado. Pressupomos, então, que o coordenador inicie a dinâmica convidando a vítima a falar sobre o fato e suas consequências. Iniciando esse primeiro grande momento da conversa, o coordenador pode formular, por exemplo, uma questão cujo conteúdo remeta, por exemplo, ao seguinte: "como você está, neste momento, quanto ao fato e suas consequências?". O coordenador convida, então, o ofensor a construir, naquela situação de enunciação, a sua compreensão do que foi falado pela vítima: "o que você compreendeu do que ele/ela disse?". A vítima, então, é convidada a enunciar se ela se sente ou não compreendida pelo ofensor, dizendo se ele compreendeu adequadamente o que ela disse ou quis dizer: "foi isso que você quis dizer?"; "você considera que ele/a compreendeu?". A vítima, nesse caso, expõe a sua verdade a respeito da compreensão feita pelo ofensor. As pessoas da comunidade podem contribuir para que a vítima identifique e expresse as consequências do 
dano em sua vida, como os impactos, sentimentos e necessidades resultantes do ato (J21, 2008a).

Podemos afirmar que, nessa situação de enunciação, a tarefa do coordenador consiste em fomentar a expressão verbal com as finalidades de 1) contribuir para que o fato passado e suas consequências sejam objetos bem definidos da atividade mental da vítima e, como tais, compreendidos por esse sujeito, do seu lugar único na existência, e de 2) valorizar o exercício de escuta das histórias enunciadas pelos demais participantes, incentivando-os a compreenderem o enunciado de outrem. Por meio do diálogo formal entre réplicas, busca-se construir uma relação dialógica entre enunciados, os quais podem se referir uns aos outros, por meio de pedidos de esclarecimentos, construções de contradições e de concordâncias às palavras do outro, entre outras tantas possibilidades.

Todo esse processo comunicativo encerra-se, na provisoriedade das relações sociais, quando o ofensor demonstra que compreendeu a perspectiva da vítima, e esta, por sua vez, sente-se satisfeita com isso. Ao longo do percurso do diálogo, toda essa tática de comunicação, centrada em um sujeito, desloca-se para a outra parte principal envolvida no conflito. Quando a comunicação inicia-se com foco na vítima, como exemplificamos anteriormente, a interação continua sequencialmente com a mesma dinâmica de indagações, orientadas, agora, para o ofensor. Feita essa tática de conversação, normalmente centrada ora na vítima ora no ofensor, ou vice-versa, buscam-se, por fim, as palavras dos sujeitos que compõem a comunidade de apoio de cada um dos envolvidos (J21, 2008).

Ainda quanto às colocações presentes no roteiro para realização do Círculo, convém destacarmos que o J21 orienta, conforme sua visão ideológica, que o coordenador elabore seus enunciados a partir de atos de fala que visem a facilitar a livre expressão dos sujeitos. Dentre essas orientações, constam, por exemplo: "perguntar ao invés de afirmar" e "formular as necessidades utilizandose das próprias palavras manifestadas pelos presentes" (J21, 2008a, p. 45). Ao não incentivar a hierarquia entre posições sociais, como seria o caso do uso de comandos com valor imperativo pelo coordenador (como: "exijo que você fale" e "você deve manifestar sua compreensão"), o J21 parece empreender uma dada busca pela liberdade da palavra.

Passemos, agora, à compreensão do segundo momento que compõe o Círculo Restaurativo: a autorresponsabilização. A ideia é que, nesse momento, os sujeitos busquem construir sentidos em torno dos fatos passados e, com isso, assumam 
a responsabilização pelas ações. Para o J21 (2008a, p. 47), o diálogo entre os participantes, com a autorresponsabilização dos presentes, tende a "fluir à medida que todos os presentes tiverem a oportunidade de se expressar e sentirem-se satisfeitos por serem verdadeiramente escutados e compreendidos" sobre o que, de fato, acreditam que estavam esperando no momento do ocorrido. Durante o encontro de palavras, o coordenador incentiva que cada sujeito exponha a sua história dos fatos, expresse possíveis dúvidas acerca de acontecimentos passados, solicite mais esclarecimentos sobre comportamentos produzidos no tempo dos fatos, apresente suas fraquezas e vulnerabilidades em relação ao ato de violência, entre outros atos. A necessidade de respostas sobre o fato passado parece ser o grande eixo desse momento.

Para subsidiar a comunicação entre os participantes, o coordenador fundamenta a sua fala em dado roteiro, resumido a seguir:

FIGURA 2 - Segundo momento do Círculo Restaurativo.

\section{AUTO-RESPONSABILIZAÇĀO - Foco nas necessidades ao tempo dos fatos}
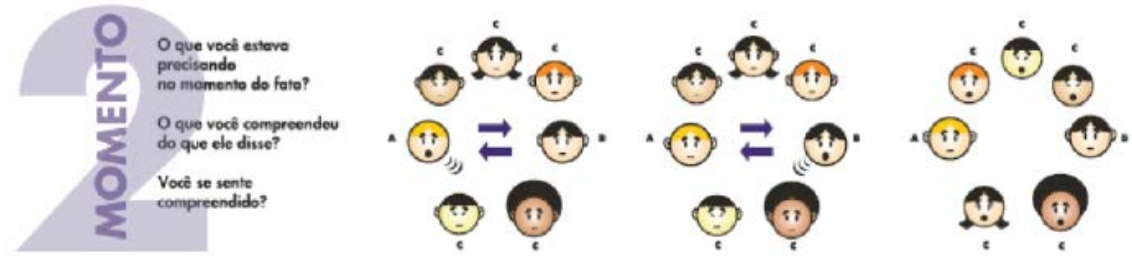

FONTE: Folder Justiça para o século 21: Instituindo práticas restaurativas, 2007. In: JUSTIÇA PARA O SÉCULO 21, 2008 c.

Iniciando esse momento do encontro, o coordenador normalmente convida o ofensor a falar acerca do fato e o que estava procurando ("ou querendo, ou desejando, ou esperando...”) quando praticou o fato: "O que você estava precisando no momento do fato?". A vítima é solicitada a construir suas contrapalavras em torno do que o ofensor falou: "O que você compreendeu do que ele disse?". O ofensor, por sua vez, é convidado a dizer se ele, do seu ponto de vista, considerase ou não compreendido: "Você se sente compreendido?". Toda essa dinâmica se repete agora pela vítima, que passa a ser o interlocutor, a quem é dirigida a pergunta inicial, acerca de suas necessidades no tempo dos fatos. A seguir, a comunidade de apoio é convidada a participar. Trata-se, portanto, da mesma dinâmica comunicacional que estrutura o momento 1 , explicado anteriormente. 
Segundo o J21, a atuação do coordenador é, nesse momento, semelhante àquela exercida no primeiro momento, na medida em que esse profissional ajuda a manter o foco da interação nas questões propostas, busca criar um espaço de enunciação no qual a compreensão do que o outro enunciou mantém-se como central. A relação com a palavra de outrem se mantém como ato primordial da interação verbal. O processo de compreensão tem, portanto, a mesma estrutura do momento anterior (um sujeito fala, o outro afirma o que entendeu e, em seguida, o primeiro menciona se foi ou não compreendido, segundo a sua perspectiva). A participação da comunidade mantém-se também semelhante à do primeiro momento.

Por fim, o Círculo conta com o terceiro momento: o acordo. Abaixo, a figura que representa essa parte da interação:

FIGURA 3 - Terceiro momento do Círculo Restaurativo.

\section{ACORDO - Foco em atender as necessidades}
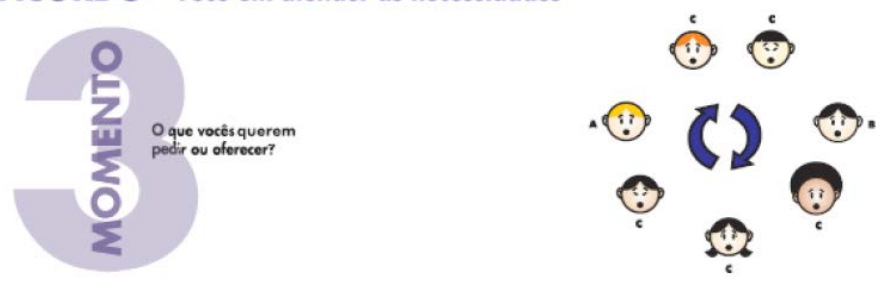

FONTE: Folder Justiça para o século 21: Instituindo práticas restaurativas, 2007. In: JUSTIÇA PARA O SÉCULO 21, 2008 c.

Nesse momento do encontro, o coordenador busca conduzir a interação com a finalidade de encorajar os sujeitos a construírem um conjunto de ações capazes de viabilizar a reparação, a compensação, o reequilíbrio, a restauração e a cura da relação prejudicada pelo conflito. $\mathrm{O}$ acordo deve ser composto por compromissos concretos e passíveis de serem realizados, prazos definidos e identificação do sujeito responsável (“o que, quanto, quem, como, quando, onde?”). O plano de ações será construído coletivamente e em consenso: quando houver divergências quanto à ação sugerida, esta não será adotada e, então, é excluída do acordo. Não podemos deixar de destacar que a liberdade do sujeito não é uma dimensão negociável em práticas restaurativas, afinal ela é considerada um direito fundamental do ser humano e "sempre que for possível estabelecer eficazmente condições alternativas, as medidas socioeducativas [como de semiliberdade e internação] deverão ser evitadas" (J21, 2008a, p. 47-48). 
Após a construção coletiva do acordo, as ações serão registradas em formulário destinado a esse fim e todos os sujeitos presentes deverão assinálo. O acordo é, então, encaminhado ao juiz responsável para que ele atribua a sentença, considerando o procedimento restaurativo. Muitas vezes, o juiz substitui a sentença, prática tradicional do modelo retributivo, pelo acordo construído no Círculo Restaurativo.

A partir da descrição do funcionamento do Círculo, é possível considerar que o encontro entre palavras com o diálogo entre diferentes réplicas é a característica que mais explicitamente sugere o diálogo formal. Essa dialogicidade formal pode contribuir para a negociação de sentidos, o terreno onde se dá a interação em todos os momentos do Círculo. Ocupando o seu lugar no processo comunicativo, o coordenador poderá criar um espaço potencialmente capaz de construir verdades, de modo que cada sujeito, na medida do possível, e dentro de suas possibilidades, não apenas se compreenda e seja compreendido pelos demais participantes, mas principalmente tenha o direito à enunciação, a expressar suas verdades.

Quanto à relação entre vítima e ofensor, não há um profissional que os represente, que por eles fale, como tradicionalmente acontece no modelo retributivo, que conta com operadores do direito, como advogados, que representam os indivíduos e seus interesses. Existe, porém, um coordenador, com capacitação na área de justiça restaurativa, que, durante a prática restaurativa, busca facilitar a comunicação entre as principais partes envolvidas. O foco da comunicação é o diálogo face a face entre os sujeitos, é o encontro entre suas palavras, que, por assim ser, só pode ser encontro entre sujeitos. O Círculo é, portanto, um espaço no qual os sujeitos, principalmente, vítimas e ofensores, podem se colocar em posição de escuta de si mesmos e do outro. E por escuta entendemos, com base nos estudos de Ponzio (2010, p. 26), a condição de "dar tempo ao outro, o outro de mim e o outro eu". Significa "dar tempo e dar-se tempo". A escuta é a busca pelo tempo disponível para a alteridade, "a alteridade de si mesmo em relação à própria identidade e a alteridade do outro em relação a sua identidade".

Consideramos que a importância desse diálogo formal entre as partes envolvidas no dano é tamanha que o J21 reitera a necessidade de eleger o diálogo como o lugar em que se busca a resolução e prevenção de situações de violência por meio de outros recursos expressivos, com as imagens. Ainda que, neste trabalho, não nos ocupemos especificamente da materialidade não verbal como realidade sígnica que remete a uma dada maneira de pensar e vivenciar relações sociais, é 
relevante aqui reforçarmos o valor que o J21 atribui ao diálogo formal enquanto dialogicidade de réplicas. Para isso, observemos a seguinte figura presente no Manual de práticas restaurativas (2008b):

FIGURA 4 - Dialogicidade formal entre réplicas expressa em linguagem não verbal empregada em material didático do J21.

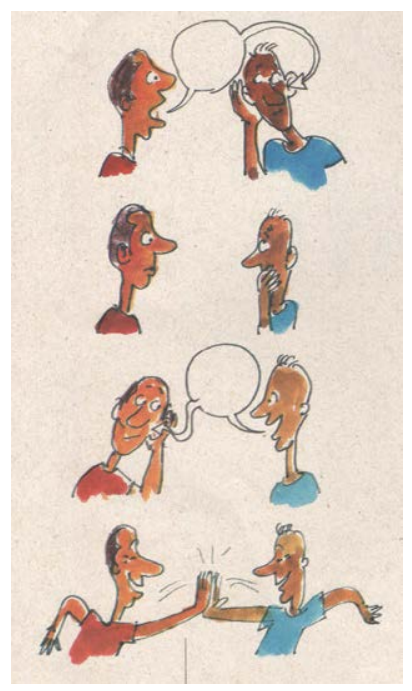

Fonte: JUSTIÇA PARA O SÉCULO 21 (2008b).

Nessa imagem, notamos que o diálogo formal é apresentado pela conversa entre dois interlocutores. São representados turnos de fala compostos pela expressão verbal e pelo calar, duas principais ações da negociação de sentidos. Por fim, não podemos deixar de assinalar que a disposição espacial dos sujeitos no formato "círculo" pode ser entendida como outra característica de diálogo formal do Círculo Restaurativo. Conforme nossa leitura, o fato de os sujeitos estarem assim dispostos fisicamente para dialogar pode ser compreendido como uma dimensão da dialogicidade formal que constitui a prática restaurativa.

Essa peculiaridade formal, assim como as demais, não é um fim em si mesma: remete a uma visão ideológica em torno das relações sociais. O termo "Círculo" foi escolhido não apenas porque exprime a disposição espacial das pessoas durante o encontro, mas sim porque "comunica os princípios de igualdade e horizontalidade objetivados nesses encontros” (J21, 2008a, p. 36). Podemos afirmar que esse 
ponto de vista adotado pelo J21 se fundamenta no trabalho de Kay Pranis (2006), com quem o J21 mantém profícuo diálogo desde a criação do projeto. Pontuando em que medida o círculo pode ser entendido como uma metáfora da concepção de relação social desejada pelas práticas restaurativas, Pranis explica que a imagem "círculo" rejeita posições hierárquicas, afinal o próprio fato de os sujeitos estarem assim dispostos pressupõe que todos estão fisicamente à mesma distância do seu centro - ninguém deve estar mais dentro ou fora - e mantêm-se interligados uns aos outros.

\section{Considerações finais}

Devido ao fato de sua estrutura comunicacional ser organizada pela busca da dialogicidade formal entre enunciados, no qual se abrem espaços para que os sujeitos efetivamente tenham direito à fala, o Círculo Restaurativo parece criar condições para o exercício da liberdade da palavra em práticas de justiça restaurativas inseridas no sistema estatal de justiça. Com este trabalho, entendemos que práticas de justiça restaurativa, ainda que estejam inseridas em estruturas altamente monológicas e fundamentadas na abordagem retributiva de justiça, como se verifica, em geral, no Poder Judiciário, têm potencial para contribuir para a liberdade da palavra, em que diferentes sentidos podem se encontrar e se confrontar em processo de justiça. A justiça passa a ser mais estritamente relacionada com a possibilidade de emergência de verdades acerca dos fatos. Desse modo, a resolução do conflito, por sua vez, passa necessariamente pela negociação de sentidos, na qual as palavras de cada sujeito são valorizadas e suas escutas são desejadas.

Nossa busca de sentido tenta projetar uma memória de futuro banhada na esperança de um humanismo da alteridade, em que a liberdade da palavra é sempre uma realidade a ser tecida, cada vez mais, nas relações sociais contemporâneas. Como afirma Paulo Freire (1996, p. 52): "sei que as coisas podem até piorar, mas também é possível intervir para melhorá-las”. É a possibilidade de mudança presente em nosso horizonte das possibilidades que direciona nossas respostas em direção à liberdade da palavra. Reconhecemos o direito da palavra de ser livre e, por isso, acreditamos na potencialidade da liberdade da palavra e na redução da liberdade de palavra. 


\begin{abstract}
In this paper, we analyse the structural elements of ideal communication between victims, offenders and their support communities, as proposed by restorative justice - a recent approach in Brazil that has been growing significantly in the last decade. The restorative movement emerges as a counterproposal to the current hundred-years-old, highly punitive, abstract and monologic model of retributive justice, by electing the dialogue between subjects as a fundamental part for the resolution and prevention of violence situations. We question the possibility of freedom of speech in restorative practices, instigated by the orientations of the restorative movement regarding face-to-face communications between the subjects that are more directly involved in the damage. For that, we seek to understand the orientations for the making of a restorative justice practice entitled "Restorative Circle". We analysed the educational books aimed at training coordinators of the Restorative Circles proposed by the Program Justice for the 21st Century, through the Restorative Practices Centre from the Childhood and Juvenile Regional Court of Porto Alegre (RS). This understanding work has its theoretical and methodological foundations in Bakhtin studies. We also touch the concept of formal dialogicity, as we consider that the Restorative Circle offers technical conditions that may take many voices to emerge in the process of justice, contributing to greater freedom of speech in judicial bodies.
\end{abstract}

Keywords: Formal dialogicity. Freedom of speech. Verbal interaction.

\title{
Referências
}

BAKHTIN, Mikhail M. (VOLOCHÍNOV, Valentin N.). Marxismo e filosofia da linguagem. Problemas fundamentais do método sociológico na ciência da linguagem. São Paulo: Hucitec, 2009. 203 p. Original publicado em 1929.

DIAS, A. B. F. Encontro de palavras em procedimentos restaurativos - uma visão possível sobre a linguagem e seu funcionamento. 2014. 251f. Tese (Doutorado em Linguística) - Centro de Educação e Ciências Humanas, Universidade Federal de São Carlos, São Carlos, 2014. Disponível em: <http://www.bdtd.ufscar.br/ htdocs/tedeSimplificado/tde_busca/arquivo.php?codArquivo=7283>. Acesso em 07 nov. 2014.

FREIRE, Paulo. Pedagogia da autonomia: saberes necessários à prática educativa. São Paulo: Paz e Terra, 1996 (Coleção Leitura). 148 p.

GERALDI, João W. Ancoragens: Estudos bakhtinianos. São Carlos: Pedro \& João Editores, 2010a. 175 p. 
GERALDI, João W. A aula como acontecimento. São Carlos: Pedro \& João Editores, 2010b. 207 p.

GERALDI, João W. Heterocientificidade nos estudos linguísticos. In: GEGe. Palavras e contrapalavras: enfrentando questões da metodologia bakhtiniana. Caderno de Estudos IV Para Iniciantes. São Carlos: Pedro \& João Editores, 2012. p. 19-39.

JUSTIÇAPARAO SÉCULO 21: INSTITUINDO PRÁTICAS RESTAURATIVAS. Iniciação em justiça restaurativa: formação de lideranças para a transformação de conflitos. Brancher, Leoberto et al. (Org.). Porto Alegre: AJURIS, 2008a. 56 p. JUSTIÇAPARAO SÉCULO 21: INSTITUINDO PRÁTICAS RESTAURATIVAS. Guia de utilização. Manual de Práticas Restaurativas. BRANCHER, Leoberto et al. (Org.). Porto Alegre: AJURIS, 2008b. 40 p.

JUSTIÇAPARAO SÉCULO 21: INSTITUINDO PRÁTICAS RESTAURATIVAS. Guia de utilização. Relatório técnico final das atividades financiadas pela SEDH. Porto Alegre, junho de 2008c. Disponível em: <http://www.justica21.org. br/ arquivos/bib_304.pdf>. Acesso em: 26 dez. 2013.

OLIVEIRA, F. N. de. Balanço das Atividades da CPR-JJJ em 2009. CPR/JJJ. Novembro, 2009. Disponível em: <http://www.justica21.org.br/arquivos/bib_377. pdf>. Acesso em: 16 dez. 2013.

PONZIO, Augusto. Procurando uma palavra outra. São Carlos: Pedro \& João Editores, 2010. 175 p.

PONZIO, Augusto. Problemas de sintaxe para uma linguística da escuta. In: VOLOCHÍNOV, Valentin N.; BAKHTIN, Mikhail M. Palavra própria e palavra outra na sintaxe da enunciação. São Carlos: Pedro \& João Editores, 2011. p. 7-57.

PONZIO, Augusto et al. Fundamentos de filosofia da linguagem. Tradução de Ephraim F. Alves. Petrópolis: Vozes, 2007. 391 p.

RIO GRANDE DO SUL. Poder Judiciário. CPR/JIJ - Central de Práticas Restaurativas do Juizado Regional da Infância e da Juventude de Poa. Apresentação [Relatório]. Porto Alegre, 27 de junho de 2013. Disponível em: <http://www. justica21. org.br/imagens/dadosj21jij.pdf>. Acesso em: 14 dez. 2013.

SCHUCH, P. Tecnologias da não-violência e modernização da justiça no Brasil: o caso da justiça restaurativa. Civitas: Revista de Ciências Sociais, Porto Alegre: EDIPUCRS, v. 3, n. 3, p. 498-520, set./dez. 2008. 
SCURO NETO, P. Por uma justiça restaurativa 'real e possível'. In: ROLIM, Marcos et al. Justiça Restaurativa: um caminho para os direitos humanos? Porto Alegre: IAJ, 2004. p. 33-43.

ZEHR, H. Trocando as lentes: um novo foco sobre o crime e a justiça. São Paulo: Palas Athena, 2008. 376p.

Submetido em: 23 de abril de 2015 . Aceito para publicação em: 30 de setembro de 2015. 